\title{
Mathematical modelling - a management tool for aquatic ecosystems?
}

\author{
K. Fedra \\ International Institute for Applied Systems Analysis; \\ Schloß Laxenburg, A-2361 Laxenburg, Austria
}

\begin{abstract}
Mathematical modelling may serve as a rational and powerful tool in the management of complex ecosystems. However, ecosystem models are drastic simplifications of the real world. As a rule they are based on a rather incomplete and scattered knowledge of the system in question. Furthermore, ecological systems and in particular marine systems are characterised by a high degree of complexity, spatial and functional heterogeneity, nonlinearity, complex behavioural features such as adptation and self-organisation, and a considerable stochastic element. Nevertheless, if management is to be based on predictions from mathematical models - and it has to be based on some kind of "model" in at least a broad sense - we need an estimate of prediction accuracy in terms of the management variables and constraints. One possible approach to model uncertainty is a probabilistic interpretation of model predictions, generated by use of Monte-Carlo techniques. Fuzzy data sets and ranges are used. The resulting model response allows the derivation of measures for model credibility. Probability distributions can be computed for certain system states under (un)certain input conditions, representing the effects of insufficient data and structural uncertainty on model-based predictions. Such analysis indicates that prediction uncertainty increases, not only with the uncertainty in the data, but also with increasing "distance" from the empirical conditions, and with time. Present ecoystem models can be a tool for qualitative discrimination between different management alternatives, rather than a credible means for detailed quantitative predictions of system response to a wide range of input conditions.
\end{abstract}

\section{ECOSYSTEM MODELLING IN A MANAGEMENT FRAMEWORK}

There is growing awareness that we need some kind of environmental management and quality control in order to "balance" the impact of our activities on the natural environment. Man's destructive capacity has reached a level where local catastrophies are only the most obvious signals of a continuous process of general and world wide environmental degradation. This might of course be understood as only the symptoms of more substantial problems in our growth-oriented world (c.f. Meadows et al., 1972); however, the symptoms are imminent and immediate decisions have to be made.

Since decisions are being made, we might ask how this is done and on what scientific basis. Decisions are made on the basis of some implicit or explicit model developed of the systems to be affected by the decision. Environmental management decisions are generally made to minimize, or at least to reduce, overall cost/benefit ratios in a multi-objective, multi-user system. This includes the maintenance of certain environmental quality standards. Part of an environmental management model must be an ecosystems submodel, which predicts the system response in terms of quality 
variables to potential management actions. This submodel is linked to the management model, which looks for the optimal strategy in the multiobjective framework. "Optimal" is defined by some kind of goal function, usually related to monetary values.

Although there is a vast and continuously growing literature on ecological modelling, this seemingly does not influence management decisions to a considerable degree. In Mason's (1979) book "The Effective Management of Resources'" on the North Sea, the term "ecology" is not even mentioned; regulation of pollution, one of the chapters, is treated as a legal, economic, and political (in a very narrow sense) problem.

Of course there are some exceptional examples of effective dialogues between decision makers and ecologists or ecosystem analysts (Clark et al., 1979), but rarely so for the marine environment. Scientists may well be asked to contribute their knowledge, but more often than not their reports are locked away in some drawers rather than affecting the management decisions. This is a very unsatisfactory situation, not least for the ecologist. For a discussion of this dilemma see e.g. Biswas (1975).

To return to the above-described ecosystem model needed for rational ecosystem management, the manager and decision maker would like to have a model he can understand, which can be proven to be reliable (cf. the discussion transcripts in Russel, 1975) - and he would like to have it right now.

\section{DATA AND MODELS}

In order to build a mathematical model - which is only a special, formal, case of building a scientific theory - we usually organize the empirical information available in such a way that part of it is used to structure the model, i.e. to specify the elements of the model and their relations. Another part of the information is used as input (in a cybernetic sense) to the model structure: this comprises the coefficients, which quantitatively describe the internal relations. In the case of a dynamic model, this also includes the forcings, imports and exports, which represent the border-crossing relations connecting the model with its environment, and finally the initial state of the model, assigning starting values to all of the elements. A third part of the available information is then used to compare the model response with what we have observed in the real world system, and by recursive adjustments of the model structure and coefficients we attempt to improve the model performance. However, the assignment of any piece of information to any of the above groups is arbitrary. Structure and coefficients cannot be estimated independently, and an operational model consists of many more simplifying assumptions than properties directly measurable in the real-world system.

A close look at the kind of data we have on ecosystems shows mainly uncertainties, variability, and sampling errors (more often than not of undetermined magnitude). In addition, ecological theory is full of contradictory hypotheses, and it is mostly impossible to rule out any of those because of lack of reliable data. Experimental evidence as a rule stems from micro-scale physiological approaches, contradictory to the richness and variety of ecosystems, and deliberately neglecting a main feature of complex ecosystems, which is the simultaneous interaction of large numbers of variables. Traditional concepts and approaches are merely extrapolations of ideas which proved to be successful in physics and chemistry. However, ecosystems are quite different from electrical 
networks and the frictionless pendulum. All these incompatibilities can be overcome only with numerous arbitrary assumptions, often enough implicitly hidden in a model formulation. The information we have at hand is of a jigsaw puzzle structure, and at best we can deduce fuzzy patterns, semiquantitative relations, ranges, and constraint condition, unless we blindly believe in numbers.

Clearly, under the above constraints the traditional deterministic techniques, using means, averages, assumptions on homogeneity and error distributions, and a firm belief in numbers have to be questioned. Forcing ecological systems into a mathematical framework, developed for vastly different systems, for the sake of ease and elegance of the analysis, seems to me not only a futile but also dangerous line of work. As a consequence, many modelbased predictions on ecosystems are either trivial or false, or at best computerized intuition of the analyst. Therefore we should not be surprised to see ecosystems analysis with only meager impact on environmental decision making and public reasoning.

\section{THE METHODOLOGY OF THE APPROACH}

There seems to be no scientific way to predict the future of a system unless we have, based on a well established theory, sufficient information on all the processes and mechanisms determining the system's evolution. Clearly, we are far from that position in ecosystems research, and it might well be questioned, whether such a position can be reached in principle. To predict, however, the future state of a system, we have to extrapolate our present knowledge in time as well as in state space - the latter to estimate the systems' response under conditions not yet experienced. This is not too bad a strategy - in fact one could say it is a basic strategy of living systems; however, this strategy is based on some most stringent assumptions: first, the present, descriptive model of the system must be good enough; second, the "distance" of projection in time as well as in state space must be related to the unpredictable (in a deterministic sense) element of variability in the system. This strategy of prediction requires a large number of assumptions, and to improve the scientific quality - and credibility - of model-based predictions, these assumptions have to be made explicit. Wherever possible, the effect of such assumptions on model predictions should be explored, so that uncertainty about the system in question will be an explicit part of the numerical analysis. Such analysis no longer results in one single answer - a single number, pretending a most unrealistic kind of precision - but a range of possible answers. The probability distributions within such ranges will partly depend on the quality of our knowledge, but also on the degree of extrapolation in time and state space, as will be shown below.

Suppose a deterministic ecoystems simulation model, relating some management variables as part of the input to some relevant quality variables as the model response. To test a model's credibility for predicting the system's response to some management alternatives, one uses a set of empirical data, describing a selected or at best average "input", which, used with the given model structure, should result in a corresponding "output". The set of data for this analysis will be - and this is not much of an unlikely assumption - scarce, scattered, noisy, and with regard to the variables measured, mostly irrelevant in terms of the management problem. Therefore, the information at hand will not allow for a detailed and reliable quantitative description of the input conditions and the corresponding systems response in terms of the variables of our model. 


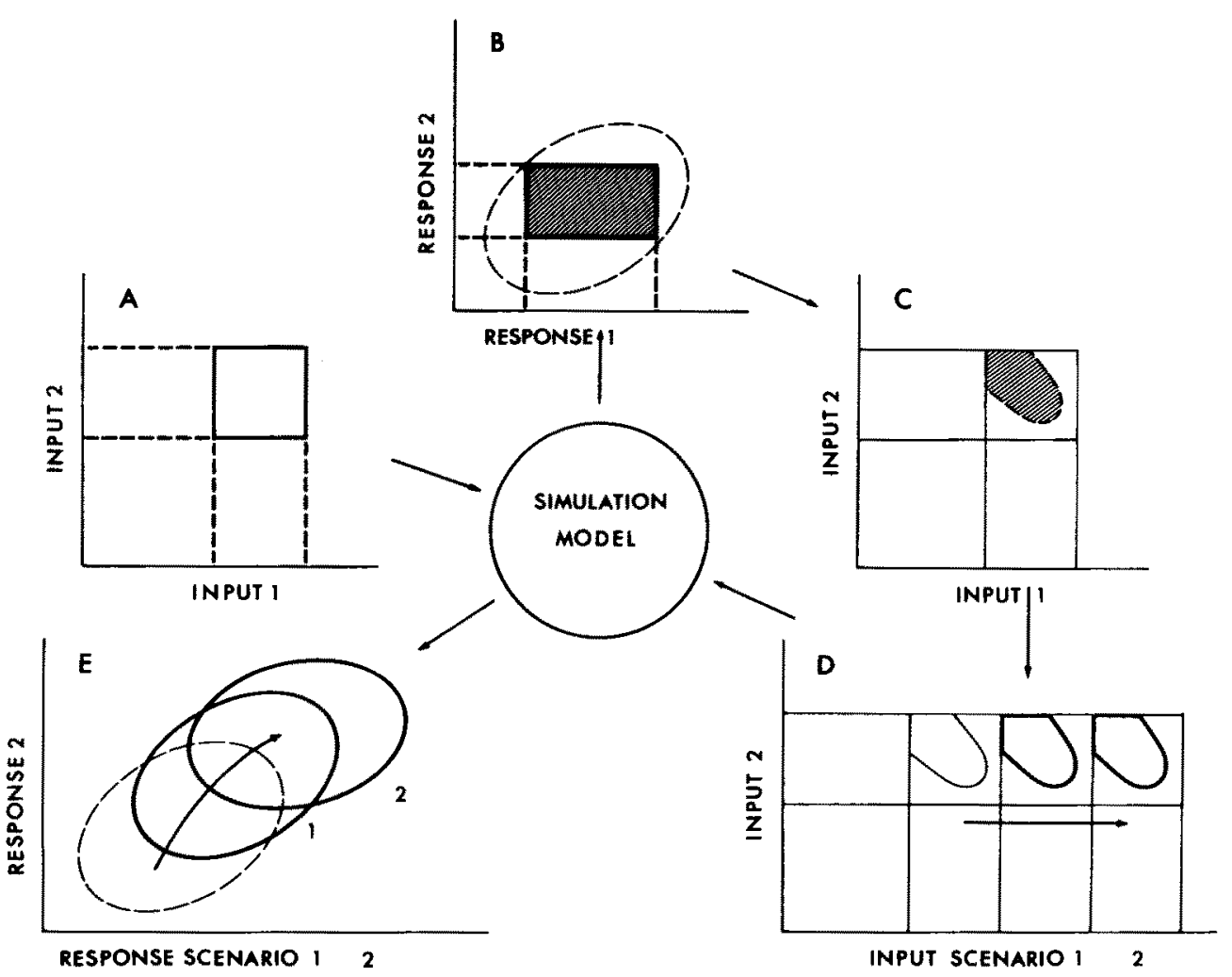

Fig. 1. Schematic summary of the approach, a two-dimensional example. (A) raw input-data space, defined by empirical ranges; $(B)$ model response corresponding to $A$, indicating the empirical range of response patterns (compare Figs, 2, 3); (C) input-data space sub-region corresponding to the empirical range in B (compare Fig. 4); (D) Input scenarios, representing e.g. management alternatives; (E) model response to D (compare Fig. 5)

Instead, one can use a more fuzzy description of the empirical system behaviour in terms of ranges for each of the observed variables (Fig. 1 B). Any such range is of course more reliable than the more or less arbitrary assignment of one single number for any measure describing the system, and thus less critical from the credibility point of view: even if objective criteria for the exact delimitation of such ranges are lacking, and again somewhat arbitrary assumptions have to be made, it seems more likely that an intersubjective agreement can be achieved on a range for a particular value, rather than on one single number. Each of these ranges, used as a constraint condition on the allowable response pattern of a model, which represents the empirical range of system behaviour, now allows an infinite set of response. But the combination of many constraining ranges and relations quickly reduces the allowable patterns. There is still an infinite number of them, of course, but by a sufficient number of constraint conditions we can delimit a meaningful region in the response space of the model.

The input required by the model for the numerical simulation of the system will also be defined by a set of ranges (Fig. 1A). Again these ranges represent various sources of 
uncertainty, and are bounded by limits of plausibility, deduced from the available empirical knowledge. The first step in the numerical analysis is then to randomly sample this input-space region, and generate a model response for each of these sample inputvectors. These sample vectors are then classified according to whether the resulting model reponse is within the region of plausible or empirical behaviour or not (Fig, 1C). Thus, by reference to the expected model behaviour, a segregation of the initial, crude input space is attempted. This is necessary, as the definition of the input space did not consider the relations and dependencies between the input data: even within plausible ranges for each value, unrealistic combinations may be sampled. However, as our knowledge about these dependencies and correlations is generally even more speculative than the knowledge on the single values empirical ranges, the a-priori specification of input-space structure will only be possible in a few cases.

A multitude of behaviour generating input-vectors can thus be generated. Their variability represents the uncertainty in the basic assumptions, and an analysis of their structural relations allows some conclusions on the adequacy of the model chosen. For predictions, where one or more input-data are changed, the whole set of input-vectors is used, as each of them is a plausible solution of the model adjustment (or calibration) procedure in the light of the basic uncertainty (Fig. 1D). Consequently, each change in the input conditions for the model, each scenario or alternative to be explored, results in a multitude of answers, which can be interpreted in a probabilistic way (Fig. 1E). Thus, the resolution or sensitivity of a model in predicting the systems response to input changes is an explicit part of the forecast. The approach is schematically summarized in Figure 1. For a detailed description of the numerical methods involved, see Fedra (1979b).

\section{RESULTS AND EXPERIENCES}

Three simulation models with largely different structure and characteristics were used to study the above approach: a trophic state prediction model for stratified water bodies, based on the lake phosphorus model of Imboden \& Gächter (1978), a modified version of a pelagic food chain model (Steele, 1974), and a primary production model for shallow, unstratified water bodies such as lagoons or shallow lakes. In each case, an appropriate data set was established from literature, specifying ranges for input data and the corresponding empirical behaviour for a given ecosystem. Almost 100000 runs of these three models, were performed, extending the simulations for up to 10 years, in order to obtain a sufficient number of runs for each model/scenario for the final analysis.

As a common feature of all three models, the percentage of successful runs in terms of the empirical behaviour constraint (Figs 2,3) was around 1 to $3 \%$. The effect of increasing "knowledge" about the system, resulting in a reduction of input data ranges, is shown in Figure 3: increasing knowledge increased the probability for a successful run giving rise to the expected model behaviour. The percentage of successful runs was about $15 \%$ for a $80 \%$ symmetric subregion of the initial input-data space.

The input-data sub-spaces, established by comparison with the behaviour defining ranges of model response, exhibited rather bizzare features. This can be attributed in part to the nonlinearities of the models used as well as to the dimensionality of the input spaces of 19,20 , and 22 input-data dimensions, respectively. As mentioned above, these 

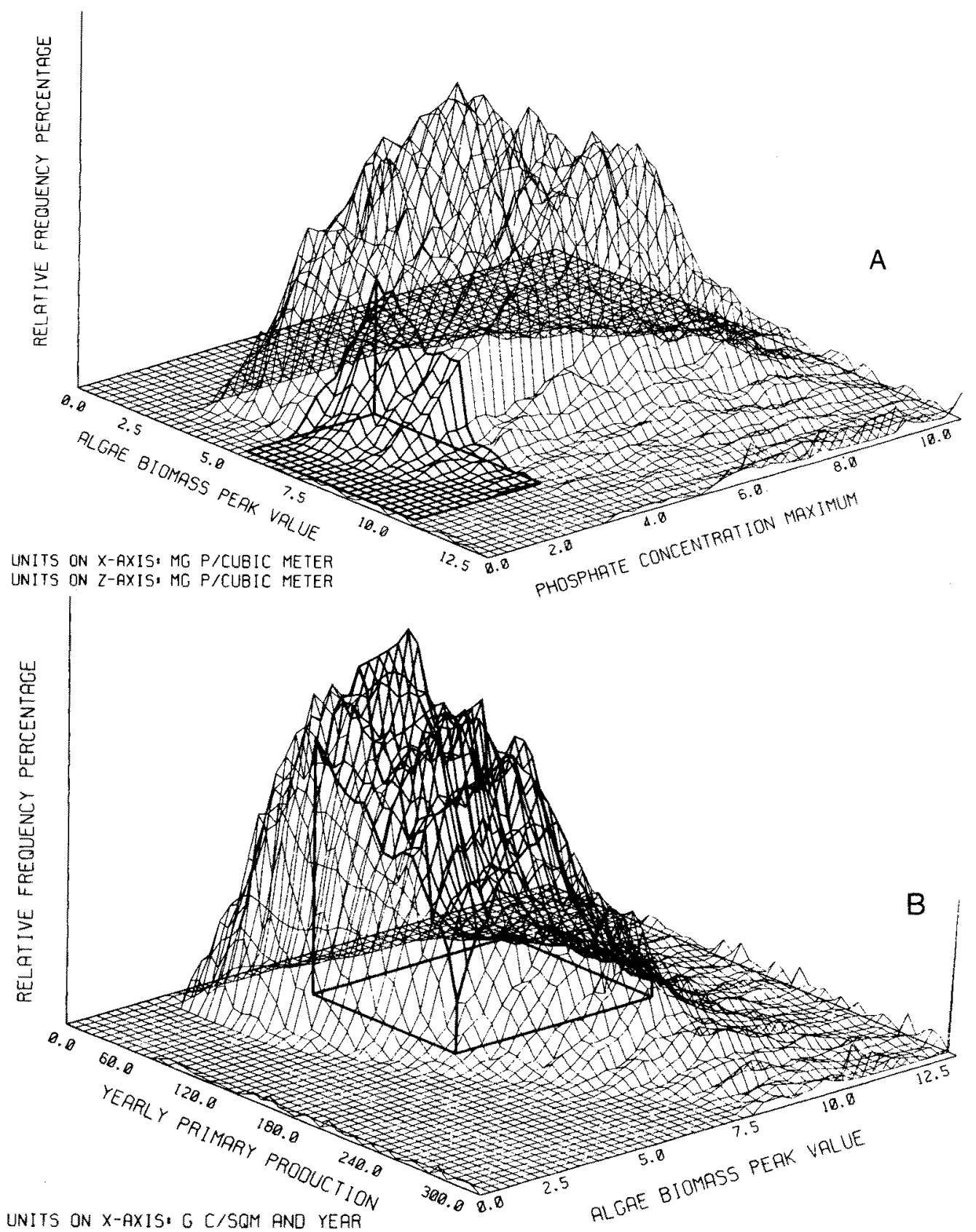

UNITS ON Z-AXIS. MO P CURIC METER

Fig. 2. Model response-space projections on planes of behaviour defining variables; 10000 model runs over a field of "plausible" input-data ranges with rectangular probability density functions. The empirical, behaviour defining range is indicated by thicker lines and the projection rectangle in the $\mathrm{x} / \mathrm{z}$ plane. The model used is based on the phosphorus/primary production model of Imboden \& Gächter (1978); model response is sensitive to the behaviour defining ranges in (A), but less in (B) 

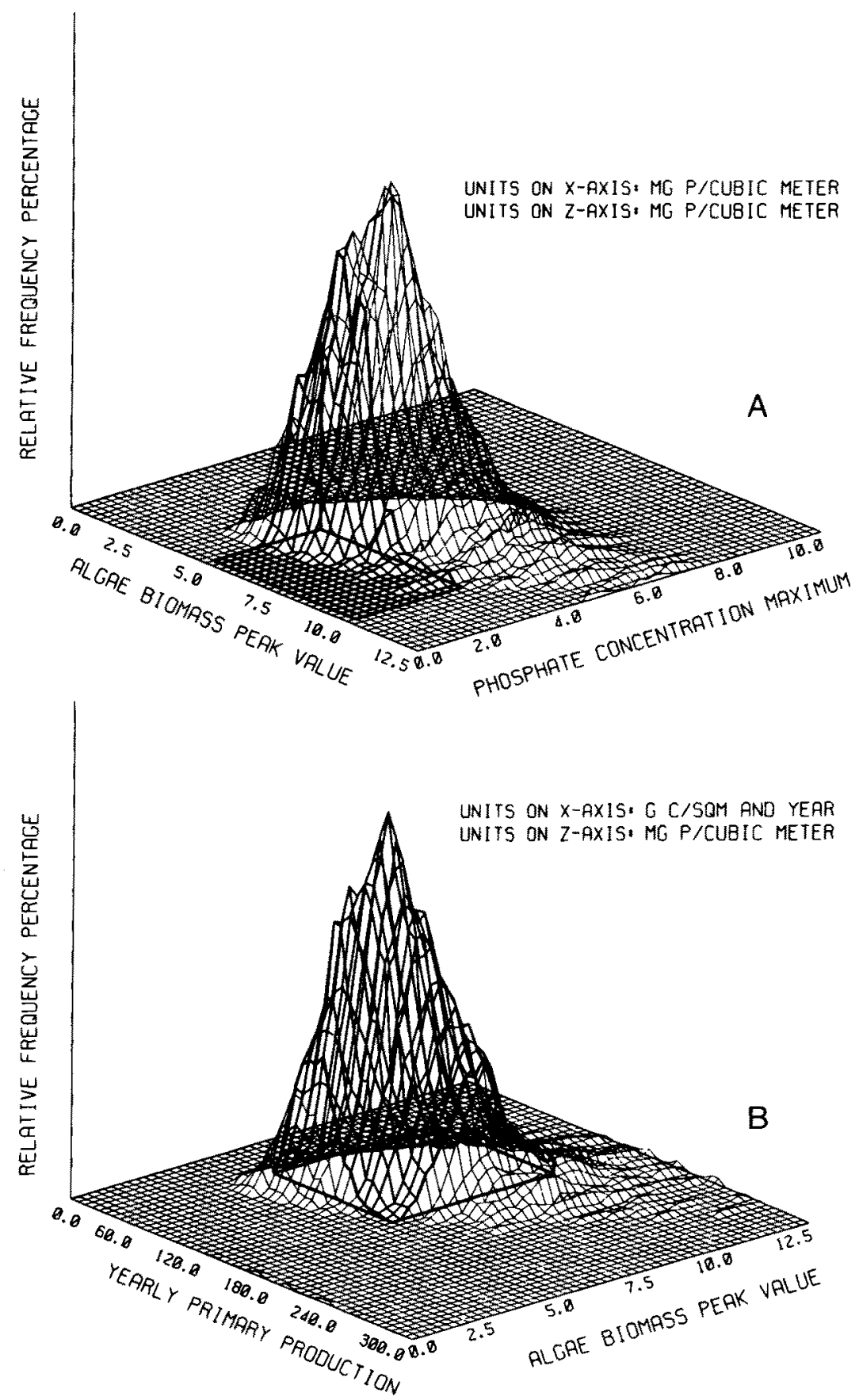

Fig. 3. Model response-space projections on planes of behaviour defining variables; 3000 model runs from a sub-region ( $80 \%$ of the single ranges, symmetric reduction) of the input-data space used for Fig. 2 
input data comprise parameters sensu stricto, imports and forcings, and initial conditions. Two examples of projections of such an input-data space are shown in Figure 4. The a-posteriori distributions within the original ranges sampled (assuming rectangular probability density functions a-priori) give some indication of model sensitivity to the input-data under the behavioural constraints. Fig. 4 a gives an example of governing parameters, significantly correlated, whereas Fig. $4 \mathrm{~b}$ shows rather independent parameters, more or less uniformly distributed. In general, the model behaviour is much more governed by the combinations and relative ratios of the input-data than their individual, absolute values. This results in the marked correlation structure of the input-data space for a given range of model response. This also indicates, that the deterministic calibration of more than one parameter is an almost futile exercise (at best a self-fulfilling tautology) as there exist no unique solutions, if the uncertainty in the data used is not assumed absent.

This first, descriptive step in the approach results in a set of input-vectors, all giving rise to the expected range of model behaviour. The variability of this set represents the uncertainty about the "true" systems state as well as the systems variability during the time of reference. For predictions of the systems response outside this empirical range of behaviour, this variability is preserved by using the whole set of input-vectors. One or a few selected elements are changed to represent the change in input conditions to be studied (Fig. 1D). For the example shown in Figure 5, nutrient input in terms of phosphorus for the trophic state model for a stratified water body was varied around an empirical range of about $1 \mathrm{mg} \mathrm{P} / \mathrm{m}^{-2} \mathrm{~d}^{-1} .21$ loading scenarios, ranging from 0 to $5 \mathrm{mg}$ $\mathrm{P} / \mathrm{m}^{-2} \mathrm{~d}^{-1}$ were simulated over a period of 10 years. This could be taken to represent, e.g., changes in regional development, watershed management, land use, agricultural practice, sewer systems installations, or the operation of wastewater treatment facilities. Model response in terms of quality variables such as orthophosphate peak concentrations, algae biomass peak, or total yearly primary production were simulated. The general patterns obtained showed:

(a) an increase in the uncertainty of the predictions (measured e.g. as coefficient of variation) with increasing uncertainty (wide ranges) in the original data for inputs and empirical systems behaviour. This is to be expected and is the most straightforward relation; (b) an increase in the uncertainty of predictions with increasing deviation from the empirical ranges of input/behaviour. Plots of coefficients of variations versus inputs show a parabolic shape, with the minimum in the empirical range; (c) an increase in the uncertainty of the predictions with time. Although the means and ranges of the predicted variables reached some kind of steady state after several years of simulation (depending on the physical characteristics of the system), the transient period was characterised by a marked increase of variability in time. Plotting coeffcients of variation versus time resulted in hyperbolic patterns, approaching asymptotically a maximum level after some years. For example, after ten years of simulation, with a large deviation from the empirical situation (more than threefold nutrient input), estimates of primary production ranged from roughly 100 to $1000 \mathrm{~g} \mathrm{C} / \mathrm{m}^{-2} \mathrm{y}^{-1}$. This is certainly a rather trivial prediction.

Some conclusions on how simulation models can possibly be improved - in terms of practical applicability - might be deduced from these experiences. First of all, for a sound test of model performance, a model has to be simple in terms of state and input dimensionality. The number of runs for a given number of sampling points per input- 

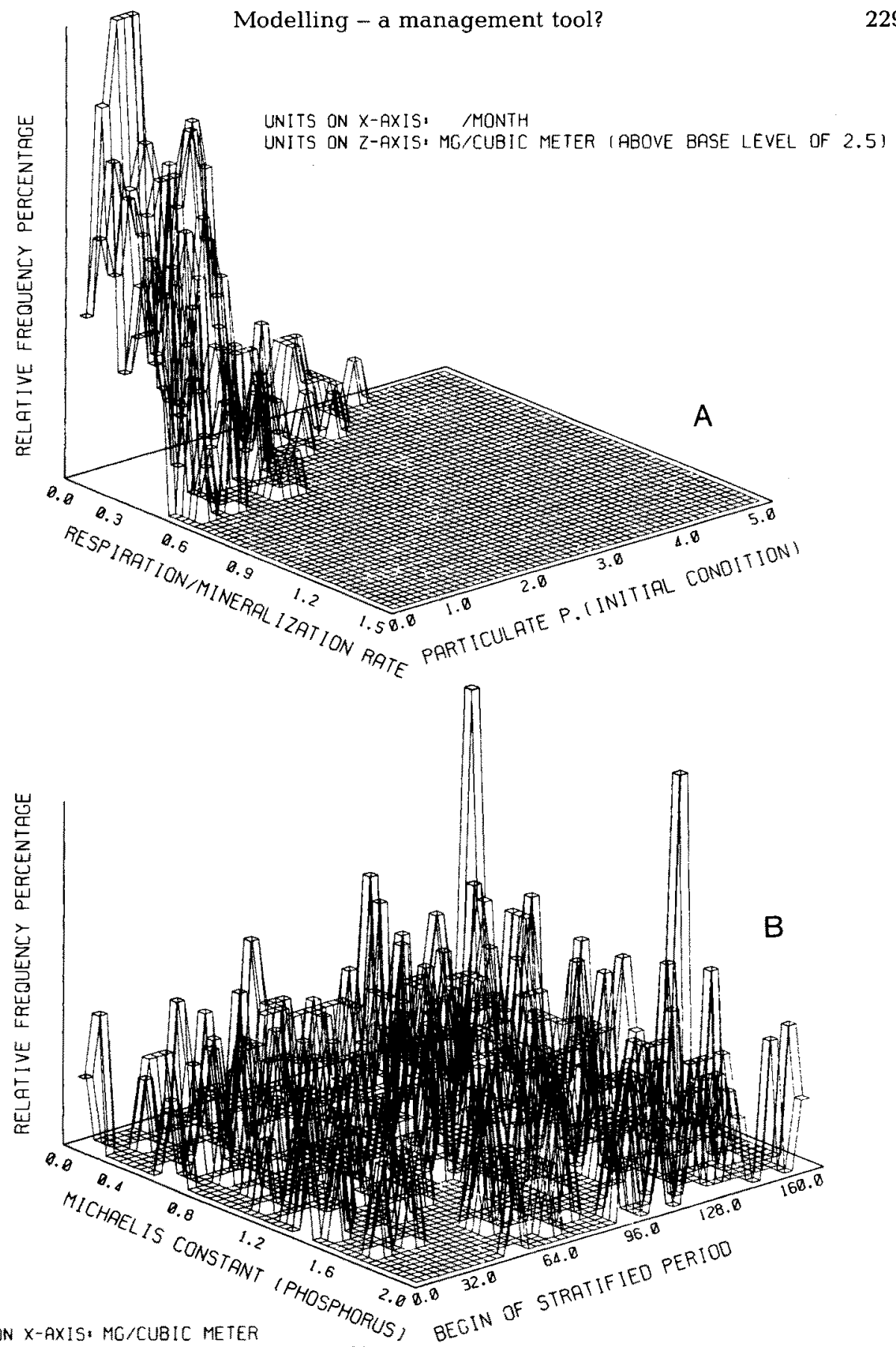

UNITS ON X-AXIS: MGACUBIC METER

UNITS ON Z-AXIS, DAY (RELATIVE TO OAY 120)

Fig. 4. Input-data space projections on planes of two input parameters; 293 data points, representing the sample inputvectors giving rise to the model response (empirical range) indicated in Fig. 1. Model response is sensitive to the input combination in (A), but not in (B) 


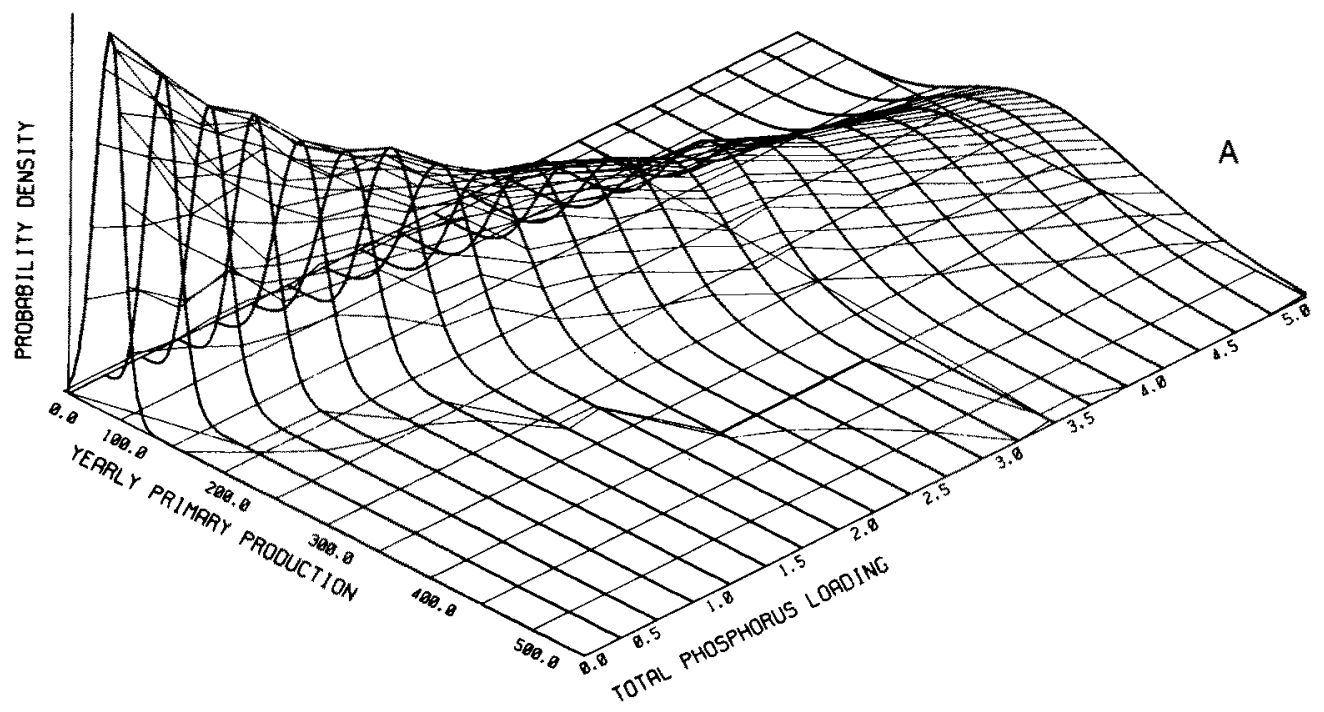

UNITS ON $X$-AXIS: G C/SOM PNO YERR UNITS ON Z-AXIS: HO P/SOM AND DAY

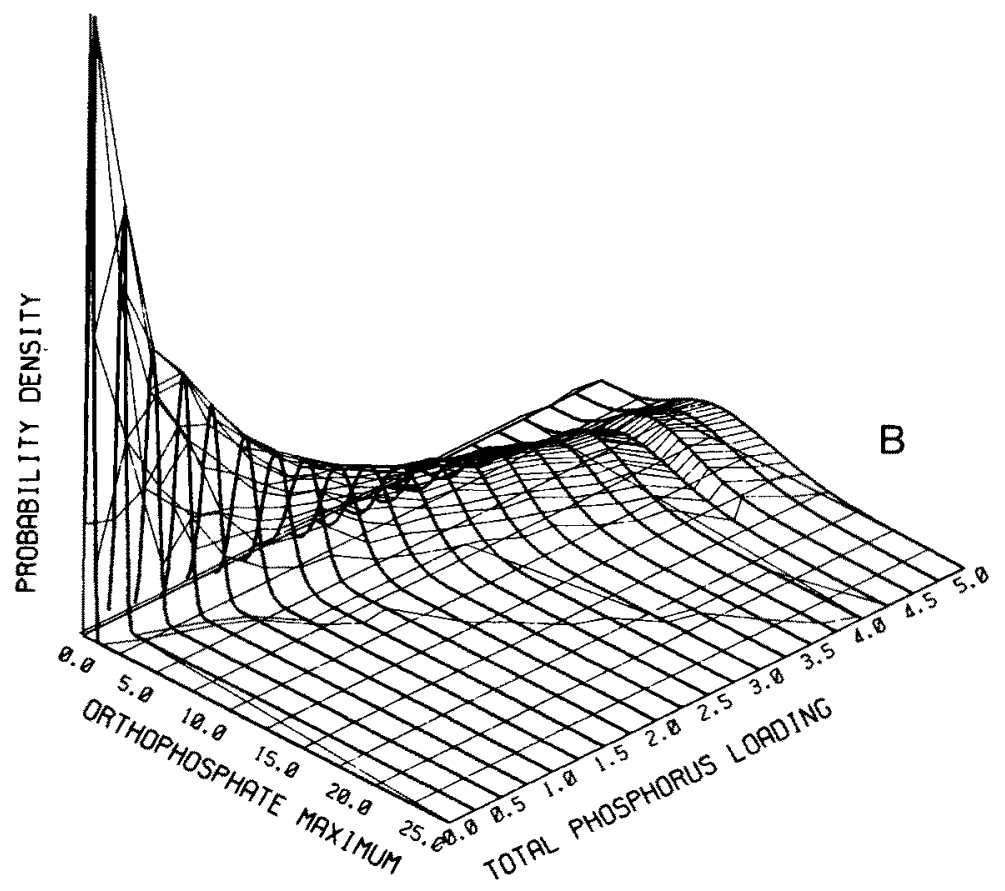




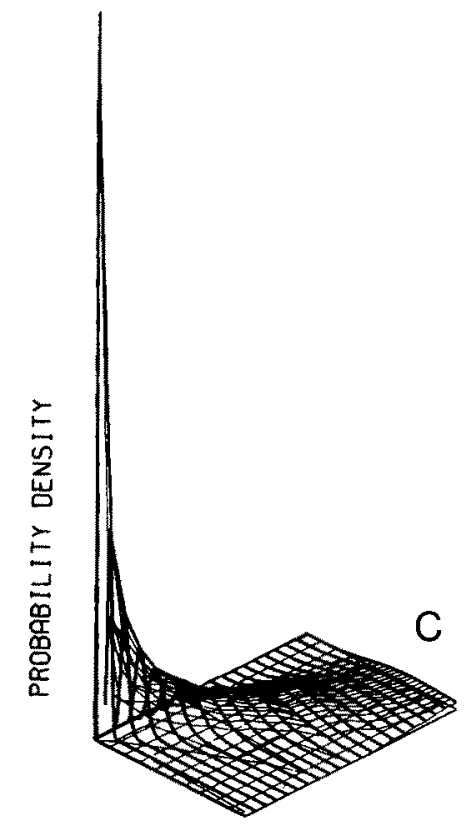

UNITS ON X-AXIS, G C/SOM RND YERR UNITS ON Z-AXIS: MG P/SOM AND DAY

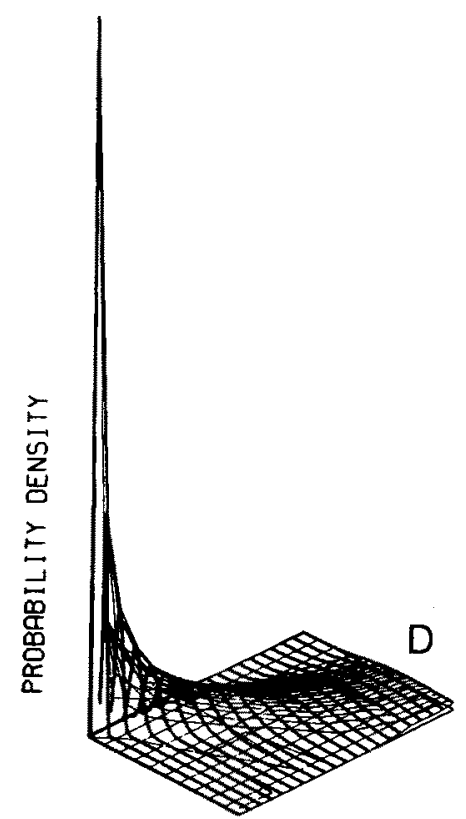

UNITS ON $X$-AXIS. 6 C/SOM AND YERR UNITS ON Z-AXIS. MG P/SOM AND DAY

Fig. 5. Probability distributions for model response predictions from a set of input-vectors; 293 runs for different nutrient loading classes, corresponding to the sample input-vectors shown in Fig. 3. Ratios between units of the three axes are kept constant for all graphs. (A) Primary production/ nutrient loading in simulation year $1 ;(B)$ orthophosphate maximum/nutrient loading in simulation year 2; (C) primary production/nutrient loading in simulation year 5; (D) primary production/ nutrient loading in simulation year 10

range, for all possible combinations, will be the number of these sampling points to the the power of the number of inputs or dimensions. This quite obviously leads rather quickly to astronomic run numbers. Analysis of complicated models with large data requirements will be technically almost impossible - at least until more elegant methods are developed. Second, models should not contain variables or parameters not directly measurable in the real world system. Data uncertainty as a major element in prediction uncertainty can be reduced only if the ranges for each of the numbers to be used in the numerical simulation can be founded on the basis of sufficient measurements or experimentation. Finally, there is also an important contribution necessary from field research: not only has the model to be appropriate to the data available, but also data collection programs will have to be designed much more in accordance with the needs of numerical analysis, if such analysis is to be used to aid real-world management decisions.

\section{DISCUSSION}

One possible method is proposed above for exploring the limits of credibility of a numerical simulation model. That there exist such limits, and that they may be narrower 
than we would like them to be, has been discussed (e.g. Hedgpeth, 1977). Also, critical evaluations have been made of implementations of systems analysis and modelling (Hilborn, 1979) and of the failures while implementing modelling into the management and decision-making process (Watt, 1977). However, for rational environmental management, the issue is very definitely on the side of having a model, even a crude one, against having no model at all (Biswas, 1975) It should be stressed that estimates of model uncertainty, and in particular prediction uncertainty, are seen as an essential criterion for model application and implementation. Some recent effort has been devoted to the estimation of model uncertainty and credibility (e.g. Di Toro \& van Straten, 1979; van Straten \& de Boer, 1979; Fedra, 1979b; Reckhow, 1979; Fedra et al., 1980), and the explicit inclusion of uncertainty in modelling studies (e.g. Walters, 1975; Spear \& Hornberger, 1978), partly in an attempt to explicitly predict probabilities for certain events or system states (Reichel \& Dyck, 1979; James et al., 1979). Also, on the implementation side, strategies to cope with uncertainty and non-unique answers are being developed (Holling, 1978; IIASA 1979).

With regard to the marine environment, comparatively few ecosystem models have been published (for some more recent examples see e.g. O'Brien \& Wroblinski, 1976; Walsh \& Howe, 1976; Vinogradov \& Menshutkin, 1977; Kremer \& Nixon, 1978). To my knowledge, none of them could claim to be used in a management context; but admittedly these models have been designed for different purposes. The situation is somewhat different when looking at lakes, rivers, and estuaries, where some successful work has been carried out and (partly) implemented (e.g. Chen \& Orlob, 1975; Bigelow \& de Haven, 1977; Bigelow et al., 1977; Bigelow et al., 1978; IAHS-AISH, 1978; Jørgensen, 1979; Scavia \& Robertson, 1979). This might partly be attributed to the fact that marine systems are generally large scale systems. Here spatial patterns play an important role (cf. Steele, 1978), but these are difficult to assess.

Marine models are often restricted to selected physico-chemical features of the environment (e.g. Goldberg et al., 1977), or to selected compartments, as in fisheries models. Extending such fishery models towards multi-species and ecosystem models (Andersen \& Ursin, 1977) results in a rather complex model with high data requirements, high dimensionality and numerous coefficients - and the consequent "educated guesswork". Without doubt, such models may play an important role in the development of environmental science. But it may well be questioned whether they can reasonably be applied to real-world management problems, as their complexity and high dimensionality is prohibitive to an analysis of their sensitivity to uncertainty.

However, the use of numerical models should promote our understanding of environmental problems. The least thing a model can do is to organize our knowledge and identify the lacunae in it (Steele, 1974). With regard to application in management problems, two major constraints are worth reiterating: first, the uncertainties in ecosystem analysis are an inevitable, principal component of the environmental systems, including man; and second, as mentioned above, environmental decision making is characterized by a demanding nowness. There is no time to measure in the field for another 10 years to reduce data uncertainty; and whatever effort is dedicated to data collection, there will always be a considerable element of uncertainty in prediction. This is not meant to discredit the importance of field data: on the contrary, the above analysis clearly showed the direct relation between prediction uncertainty and the quality of 
data. This rather aims at a reconsideration of the questions we might reasonably expect a mathematical model to answer, and consequently the design of such models. Models for

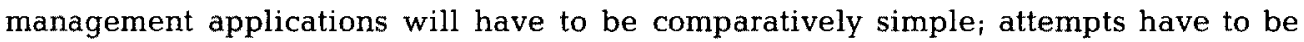
made to capture natural complexity in a manner other than adding mechanistic detail (see e.g., Fedra, 1979a; Straskraba, 1979).

Clearly, considering the above, the answers obtainable from the most sophisticated model are hardly reliable in quantitative terms. Although the computer will of course produce numbers, it is not their arithmetic precision, but their meaning which matters. As the answer will always be some number, the question must be put in an appropriate way. This amounts to the formulation of alternative hypotheses, which then can be tested by means of the computer. This is somewhat comparable to hypothesis testing in mathematical statistics. It is not the actual value of the test statistic which matters, but whether it forces us to reject our hypothesis or not. In terms of management application of ecosystem models, this would mean a more or less qualitative discrimination between several management alternatives, some kind of ranking according to performance criteria of the possible strategies. This of course requires a rather careful and elaborate formulation of the management alternatives and performance criteria; and it has to be understood that a mathematical model can only be a tool for ecosystem management, if the basic environmental and management problem is well formulated for the numerical analysis.

Acknowledgements. The research described in this report was supported by the research grant No. 3905 of the Austrian Fonds zur Förderung der wissenschaftlichen Forschung. The author is indebted to B. Schweeger from IIASA Computer Services for his introductory help with computer graphics, and to I. Fisher for his linguistic help.

\section{LITERATURE CITED}

In an effort to make this bibliography as current as possible, works are included which are presently available only as publications of the International Institute for Applied Systems Analysis (IIASA). These may be obtained from: Documents and Publications, International Institute for Applied Systems Analysis, Schloß Laxenburg, A-2361 Laxenburg, Austria.

Andersen, K. P. \& Ursin, E., 1977. A multispecies extension of the Beverton and Holt theory of fishing, with accounts of phosphorus circulation and primary production. - Meddr Danm. Fisk. og Havunders. N. S. 7, 319-435.

Bigelow, J. H. \& De Haven, J.C., 1977. Protecting an estuary from floods - policy analysis of the Oosterschelde. Vol. V: Anaerobic conditions and related ecological disturbances. - RAND, R2121/5-NETH.

Bigelow, J. H., Bolten, J. G. \& De Haven, J. C., 1977. Protecting an estuary from floods - a policy analysis of the Oosterschelde. Vol. 4: Assessment of algae blooms, a potential ecological disturbance. - RAND, R-2121/4-NETH.

Bigelow, J. H., Dzitzer, C. \& Peeters, J. H., 1978. Protecting an estuary from Floods - a policy analysis of the Oosterschelde. Vol. 2: Assessment of long-run ecological balances: an addendum (calibration data). - RAND, R-2121/3A-NETH.

Bigelow, J. H., De Haven, J.C., Dzitzer, C., Eilers, P. \& Peeters, J. C. H., 1977. Protecting an estuary from floods - a policy analysis of the Oosterschelde. Vol. 3: Assessment of long-run ecological balances. - RAND, R-2121/3-NETH.

Biswas, A. K., 1975. Mathematical modelling and environmental decision-making. - Ecol. Modell. $1,31-48$. 
Chen, K. W. \& Orlob, G. T., 1975. Ecological simulation for aquatic environments. In: Systems analysis and simulation in ecology. Ed. by B. C. Patten. Acad. Press, New York, 3, 475-587.

Clark, W. C., Jones, D. D. \& Holling, C. S., 1979. Lessons for ecological policy design: a case study of ecosystem management. - Ecol. Modell. 7, 1-53.

Di Toro, D. M. \& van Straten, G., 1979. Uncertainty in the parameters and predictions of phytoplankton models. International Institute for Applied Systems Analysis, Laxenburg, 34 pp. (WP-79-27).

Fedra, K., 1979a. Modelling biological processes in the aquatic environment (with special reference to adaptation). International Institute for Applied Systems Analysis, Laxenburg, 56 pp. (WP-7920).

Fedra, K., 1979b. A stochastic approach to model uncertainty: a lake modelling example. International Institute for Applied Systems Analysis, Laxenburg, 46 pp. (WP-79-63).

Fedra, K., van Straten, G. \& Beck, M. B., 1980. Uncertainty and Arbitrariness in ecosystems modelling: a lake modelling example. International Institute for Applied Systems Analysis, Laxenburg, $39 \mathrm{pp}$. (WP-80-87).

Goldberg, E. D., McCave, I. N., O'Brien, J. J. \& Steele, J. M. (Eds), 1977. Marine modelling. WileyInterscience, New York, 895 pp.

Hedgpeth, J. W., 1977. Models and muddles. Some philosophical observations, - Helgoländer wiss. Meeresunters. 30, 92-104.

Hilborn, R., 1979. Some failures and successes in applying systems analysis to ecological systems. J. appl. Systems Analysis 6, 25-31.

Holling, C. S., (Ed.), 1978. Adaptive environmental assessment and management, Wiley, Chichester, $377 \mathrm{pp}$.

IAHS-AISH, 1978. Modelling the water quality of the hydrological cycle. Proceedings of the Baden Symposium, Sept. 1978. IAHS-AISH Publ. 125, 1-382.

Imboden, D. \& Gächter, R., 1978. A dynamic lake model for trophic state prediction. - Ecol. Modell. 4, 77-98.

International Institute for Applied Systems Analysis,1979. Adaptive environmental assessment and management: current progress and prospects for the approach. Summary report of the first Policy Seminar 18-21 June, 1979. International Institute for Applied Systems Analysis, Laxenburg, CP$79-9,123 \mathrm{pp}$.

James, L. D., Bowles, D. S., James, R. W. \& Canfield, R. V., 1979. Estimation of water surface elevation probabilities and associated damages for the Great Salt Lake. Utah State University, Water Resources Planning Series UWRL/P-79/03, $182 \mathrm{pp}$.

Jorgensen, S.E. (Ed.), 1979. State-of-the-art in ecological modelling. Proceedings of the Conference on Ecological Modelling, Copenhagen, Denmark, 28 August-2 September 1978. International Society for Ecological Modelling, $891 \mathrm{pp}$.

Kremer, J. N. \& Nixon, S. W., 1978. A coastal marine ecosystem: simulation and analysis. Springer, Berlin, $217 \mathrm{pp}$.

Mason, C. M. (Ed.), 1979. The effective management of resources. The international politics of the North Sea. Frances Pinter, London, $268 \mathrm{pp}$.

Meadows, D. H., Meadows, D. I., Randers, J. \& Behrens, W. W., 1972. The limits to growth. Universe Books, New York, 205 pp.

O'Brien, J. J. \& Wroblisnki, J. S., 1976. A simulation of the mesoscale distribution of the lower marine trophic levels off West Florida. In: Systems analysis and simulation in ecology. Ed. by B. C. Patten. Acad. Press, New York, 4, 63-110.

Reckhow, K. H., 1979. Empirical lake models for phosphorus: development, applications, limitations and uncertainty 193-222. In: Perspectives on lake ecosystem modeling. Ed. by D. Scavia \& A. Robertson. Ann Arbor Science Publ, Ann Arbor, Mich., 183-221 pp.

Reichel, F. \& Dyck, S., 1979. Stochastische geohydraulische Berechnungsverfahren für die Projektierung der Tagbauentwässerung - Notwendigkeit, Ziele, Verfahren. - Neue Bergbautechn. 9 (1), 6-10.

Scavia, D. \& Robertson, A. (Eds.), 1979. Perspectives on lake ecosystem modeling. Ann Arbor Science, Publ., Ann Arbor, Mich. 326 pp.

Spear, R. C. \& Hornberger, G. M., 1978. Eutrophication in Peel Inlet: an analysis of behaviour and sensitivity of a poorly defined system. - Cres. Rep. AS/p 24, 99 pp.

Steele, J. H., 1974. The structure of marine ecosystems. Harvard Univ. Press, Cambridge, 128 pp. 
Steele, J. H. (Ed.), 1978. Spatial patterns in plankton communities. Plenum Press, New York, 470 pp. (NATO Conference Series, Ser. 4: Marine Sciences, Vol. 3).

Straskraba, M, 1979. Natural control mechanisms in models of aquatic ecosystems. - Ecol. Modell. $6,305-321$.

van Straten, G. \& de Boer, B., 1979. Sensitivity to uncertainty in a phytoplankton-oxygen model for lowland streams. International Institute for Applied Systems Analysis, Laxenburg, WP-79-28, 21 pp.

Vinogradov, M. E. \& Menshutkin, V. V., 1977. The modeling of opensea ecosystems. In: Marine modelling. Ed. by E. D. Goldberg, J. N. McCave, J. J. O'Brien \& J. M. Steele. Wiley-Interscience, New York, 891-921.

Walsh, J. J. \& Howe, S. O., 1976. Protein from the sea: a comparison of the simulated nitrogen and carbon productivity of the Peru upwelling ecoystem. In: Systems analysis and simulation in ecology. Ed. by B. C. Patten. Acad. Press, New York, 4, 47-61.

Walters, C. J, 1975. Optimal harvest strategies for salmon in relation to environmental variability and uncertain production parameters. - J. Fish. Res. Bd Can. 32, 1777-1784.

Watt, K. E. F., 1977. Why won't anyone believe us? - Simulation 28, 1-3. 